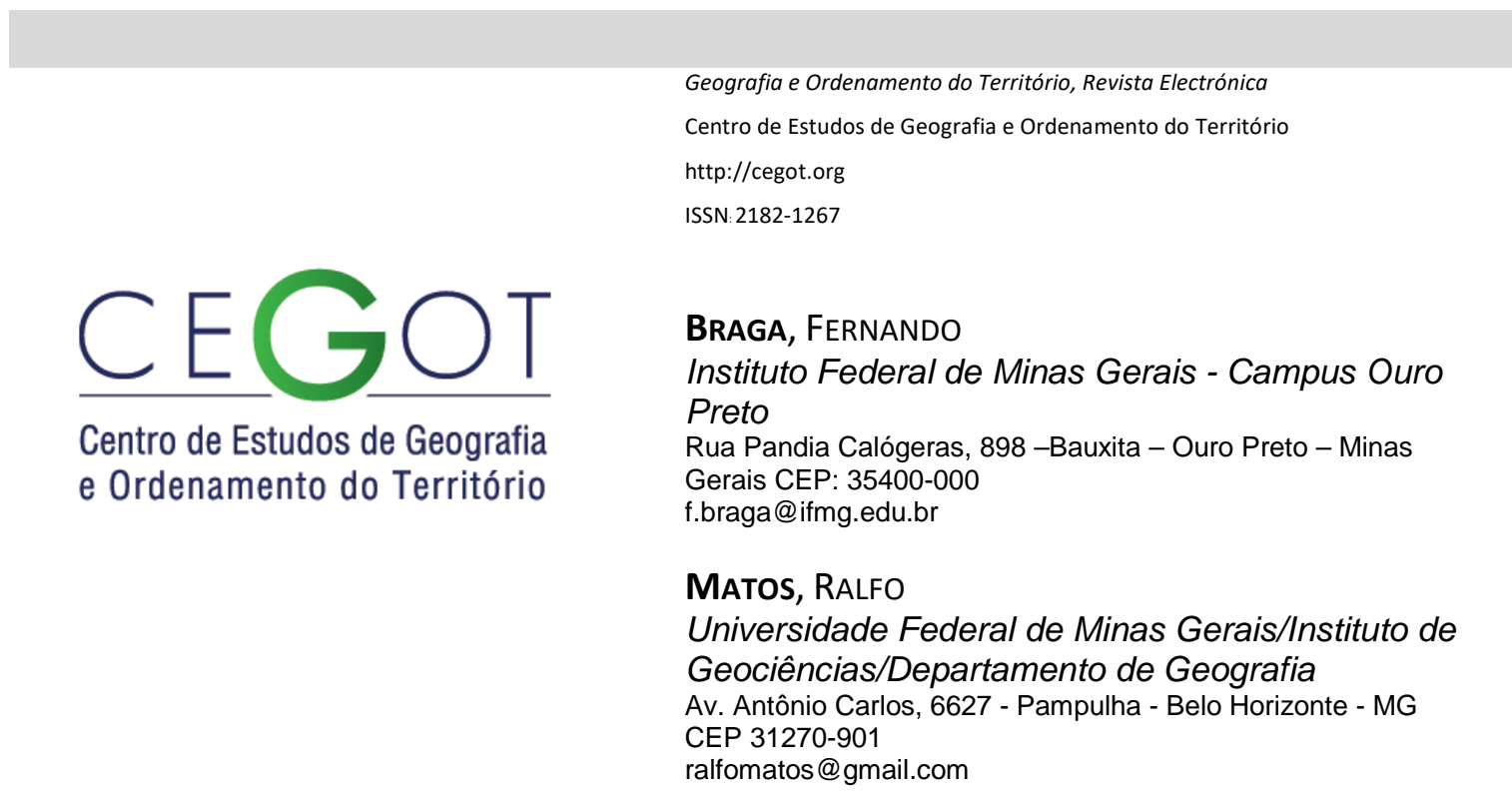

\title{
Quem são os migrantes das metrópoles? Uma análise comparativa das pessoas que entraram e saíram das regiões metropolitanas brasileiras
}

Who migrates in metropolitan areas? A comparative analysis of people moving in and out

Referência: Braga, Fernando; Matos, Ralfo (2017). Quem são os migrantes das metrópoles? Uma análise comparativa das pessoas que entraram e saíram das regiões metropolitanas brasileiras. Revista de Geografia e Ordenamento do Território (GOT), n.o 11 (junho). Centro de Estudos de Geografia e Ordenamento do Território, p. 59-81, dx.doi.org/10.17127/got/2017.11.003

\section{RESUMO}

A migração interna foi fator chave no crescimento metropolitano brasileiro impulsionado pela transição da economia nacional da base agrícola para a urbano-industrial. Nas três últimas décadas, contudo, vêm ocorrendo mudanças significativas na intensidade e direção dos fluxos populacionais, bem como no perfil dos migrantes. Além disso, os dados mais recentes mostram uma tendência de inversão de sinal do saldo migratório das regiões metropolitanas. Diante disso, esse artigo propõe analisar comparativamente os imigrantes e os emigrantes das 12 principais regiões metropolitanas do Brasil em dimensões demográficas e socioeconômicas a partir dos dados dos Censos Demográficos de 1991 e 2000, possibilitando uma reflexão sobre as mudanças recentes na mobilidade populacional brasileira e sua relação com o processo de formação da rede urbana.

Palavras-chave: Regiões Metropolitanas, Migrações Internas, Seletividade Migratória, Censo Demográfico 


\begin{abstract}
Internal migration was a key factor in the Brazilian metropolitan growth driven by the transition from an agricultural economy to the urban-industrial. In the last three decades, however, changes in the intensity and direction of flows and also in the caracteristics of migrants have been going on. Moreover, the latest data show a tendency to signal inversion of net migration in metropolitan areas. This article proposes to examine comparatively immigrants and emigrants of 12 major metropolitan areas of Brazil in demographic and socioeconomic dimensions using the data of 1991 and 2010 Census, allowing a reflection on the recent changes in the Brazilian population mobility and its relation to the process of formation of the urban network.
\end{abstract}

Keywords: Metropolitan Regions, Internal Migration, Selectivity on Migration, Population Census

\title{
1. Introdução
}

Este artigo propõe uma reflexão sobre o papel das metrópoles na rede migratória brasileira a partir de uma análise comparativa entre os imigrantes e os emigrantes das principais regiões metropolitanas. A comparação foi realizada em dimensões demográficas e econômicas que permitissem distinguir esses dois grupos quanto ao seu perfil e, secundariamente, quanto a contribuição nos locais de destino. A questão chave a ser debatida aqui é a seletividade migratória e a forma como ela opera na determinação daqueles que entram e saem das metrópoles.

A importância das migrações internas para a constituição das metrópoles é tema recorrente na literatura especializada (Balan, 1973; Graham e Holanda Filho, 1980; Martine, 1987). Com as taxas de fecundidade declinantes deste a década de 1970 , especialmente nas cidades, o crescimento natural da população respondeu por uma pequena parcela da impressionante crescimento urbano que o país vivenciou na segunda metade do século XX. Contudo, a maioria destes movimentos, que era de tipo rural-urbano, perdeu expressão no cômputo geral das migrações internas, dando lugar aos fluxos de tipo urbano-urbano dentro e fora das regiões metropolitanas. O cenário atual é de estabilização do peso dos migrantes na população total, em contraste com aumento dos lugares de origem e destino, reflexo da expansão da rede urbana nacional em tamanho e hierarquia (Braga e Fazito, 2010). Neste 
contexto, cumpre investigar as pessoas que atualmente entram e saem das metrópoles, de modo a desvendar parte dos processos socioespaciais que fundamentam esses movimentos. Nas últimas décadas, o Brasil sofreu profundas modificações que levaram à reorganização da economia e à transformação da organização territorial: redemocratização, desconcentração espacial da indústria, reestruturação produtiva, abertura econômica, formação de clusters produtivos locais, entre outros. Cada um destes processos tem ampliado o caráter seletivo das migrações internas como efeito do crescimento urbano e modernização da estrutura produtiva nacional. Neste sentido, é indispensável conhecer melhor a população em movimento, de modo a compreender como os migrantes fazem suas escolhas. As teorias sobre migração elaboradas no contexto do processo de modernização do século XX dialogam cada vez menos com os processos mais atuais, o que justifica o contínuo esforço de interpretar o que vem ocorrendo com a mobilidade populacional no país.

\section{As migrações internas no Brasil contemporâneo}

O texto de Martine (1980) é uma das obras de referência sobre a seletividade e adaptação dos migrantes internos no Brasil. O autor faz uma revisão crítica dos trabalhos publicados na década de 1970 sobre os imigrantes das áreas urbanas. A despeito das diferenças metodológicas, os estudos parecem convergir em demonstrar que a situação geral dos imigrantes melhora com o passar do tempo, muitas vezes com os imigrantes se saindo melhor do que os não-migrantes. Não obstante, muitos dos estudos que apontaram a melhora com o tempo de residência desconsideravam os altos índices de reemigração. Os dados disponíveis indicavam, por exemplo, que $20 \%$ dos imigrantes de Belo Horizonte não resistiam a uma temporada de cinco anos na cidade, bem como $40 \%$ reemigravam antes de completar nove anos de residência ${ }^{1}$.

\footnotetext{
${ }^{1} \mathrm{O}$ mais importante diferencial entre aqueles que conseguiam sucesso no empreendimento migratório era a escolaridade (Martine, 1980).
} 
Apesar do insucesso de uma parcela dessa população, a migração foi um importante componente da mobilidade social observada no Brasil durante a década de 1970. A emergência da sociedade urbano-industrial brasileira na segunda metade do século $X X$ foi acompanhada por uma mobilidade ascendente em quase todos os estratos da sociedade. Esse fenômeno se explica, em grande medida, pelos efeitos da industrialização, bem como pela expansão da oferta de educação. Como mecanismo interveniente do processo de modernização, a migração para as áreas urbanas proporcionou a milhões de pessoas o ambiente favorável para alcançar estratos superiores da pirâmide social (Januzzi, 1999).

Utilizando dados de painel das trocas populacionais entre os Estados brasileiros desde a década de 1950, Netto Junior e Targino (2003) mostraram que as migrações internas brasileiras confirmam a tendência dos fluxos se dirigirem predominantemente para as áreas de maior crescimento do produto interno bruto, contudo, os modelos estimados também mostraram que a migração não teve o efeito de equalizar os produtos per capita regionais. Ramos e Araujo (1999) mostraram que os migrantes se moveram para as áreas de dinamismo econômico, independentemente das taxas de desemprego alto, sendo atraídos pela expectativa de renda. Neste sentido, as migrações internas brasileiras na segunda metade do século XX têm boa aderência às teorias que associam a migração ao processo de modernização e aos desequilíbrios regionais criados pelo processo desigual no espaço de acumulação do capital (Gaudemar, 1977; Singer, 1985).

A partir da década de 1980, contudo, a dinâmica econômica e territorial confere novos contornos à mobilidade populacional. Ao invés do crescimento acelerado observado na década anterior, o país ingressa em um período marcado pela hiperinflação e estagnação, resultado, em grande medida, do alto endividamento público levado a cabo pelo processo de modernização conservadora comandado pelos militares (Becker, 1991). O cenário de crise estanca o anterior processo de mobilidade social e o êxodo rural dá os primeiros sinais de arrefecimento (Jannuzi, 1999).

\footnotetext{
2 Januzzi (1999) alerta que a mobilidade social da década de 1970 é acompanhada, paradoxalmente, de aumento das desigualdades. De fato, quase todos os estratos sociais experimentam mobilidade, mas no caso dos estratos inferiores, no qual se encontrava a maioria dos migrantes, a mobilidade se operou em categorias contiguas, por exemplo, de "trabalhadores rurais não-qualificados" para "trabalhadores urbanos nãoqualificados e semiqualificados".
} 
No tocante à organização do território, sentem-se os impactos da dinâmica da indústria brasileira, que começa a se desconcentrar espacialmente em virtude, principalmente, das deseconomias de aglomeração da área metropolitana de São Paulo e do efeito das políticas de desenvolvimento regional do governo militar (Diniz, 1993; Matos, 1995). As migrações de tipo urbano-urbano vão ganhando protagonismo sobre o êxodo-rural. Além disso, as regiões metropolitanas do Rio de Janeiro e São Paulo começam a enviar um número significativo de migrantes para áreas de desconcentração demográfica, especialmente nas regiões Sul e Sudeste. Esses migrantes, mais qualificados e preparados para o mercado de trabalho urbano, começam a contribuir decisivamente para o desenvolvimento econômico dos espaços com maior crescimento na rede urbana nacional (Matos, 2002).

Conquanto as profundas reformas da década de 1990 tenham permitido a retomada do crescimento econômico, o preço da reestruturação produtiva e da agenda neoliberal do Estado foi o aprofundamento das desigualdades sociais e do desemprego (Cano, 2011). Utilizando dados da década de 1990, Biagioni (2009) analisou a condição dos imigrantes do Estado de São Paulo. Segundo o autor, durante a década de 1990 não houve mobilidade social estrutural no Brasil, apenas mobilidade circular. Apesar dos imigrantes de São Paulo apresentarem taxas maiores de mobilidade que os não-migrantes, estes ainda estavam mais concentrados nas ocupações manuais.

A restrição nas possibilidades de mobilidade social teve impacto decisivo sobre as migrações internas. As grandes correntes migratórias das décadas passadas perdiam força, enquanto surgiam clusters imigratórios em meio a regiões de tradição emigratória. Na rede urbana nacional, as cidades médias ganharam protagonismo ao lado das antigas e novas metrópoles (Braga, 2011).

Os dados do Censo de 2000 mostraram que as áreas de desconcentração produtiva e demográfica se tornaram mais seletivas à imigração. Na complexa dinâmica de reestruturação da rede urbana nacional, os polos econômicos da porção Centro-Sul do país continuavam atraindo migrantes qualificados, muitos dos quais com prévia experiência nas áreas metropolitanas do Rio de Janeiro e São Paulo (Matos e Nunes, 2004).

A primeira década do século XXI foi marcada pela continuidade do crescimento econômico, com impactos sobre a redistribuição da renda. Alguns fatores se combinaram para permitir 
o fenômeno: bom desempenho econômico do país no mercado de commodities, valorização do salário mínimo e ampliação dos programas sociais (Cano, 2011). No geral, esse desempenho promoveu um ligeiro aumento das migrações internas, até mesmo com aumento dos movimentos do Nordeste em direção ao Sudeste (Baeninger, 2012). Longe de perder o seu dinamismo, as migrações internas ainda refletem os avanços e reveses da economia nacional.

Em um esforço parecido com o que está proposto neste artigo, Cunha e Jakob (1999) traçaram o perfil da população que entrava e saía da Região Metropolitana de São Paulo, buscando compreender qual era o impacto das migrações na população residente na metrópole. As análises focalizaram a comparação entre a população da metrópole observada (com os migrantes) e estimada, sem nenhum efeito da migração. Os resultados confirmaram a hipótese de que, apesar do aumento da seletividade migratória em relação à década de 1970, a imigração para a RMSP cumpre o papel de rejuvenescer a população residente, com mais pessoas em idade ativa, ao mesmo tempo em que reduz a escolaridade média da população.

Esses resultados parecem sugerir que a seletividade migratória opera de forma diferenciada no território. Nas metrópoles, ainda existem mais oportunidades para migrantes menos qualificados, bem como mais acesso aos meios de ascender socialmente, principalmente pela melhora do nível educacional. Ao mesmo tempo, constata-se uma ampliação da emigração das áreas metropolitanas, na qual se destacam os indivíduos mais qualificados que se dirigem, sobretudo, aos espaços de desconcentração produtiva.

Torna-se necessário, então, requalificar a reemigração constatada por Martine (1980) para os fluxos da década de 1970. Na clássica interpretação de que a migração se dava por etapas (Ravenstein, 1980; Lee, 1980), entendia-se que migrar consistia em uma mudança definitiva e, por isso, o retorno migratório era frequentemente associado ao fracasso dos menos adaptados. Isso não parecer ser a regra em sociedades que já alcançaram certo nível de modernização e urbanização e que ampliaram sensivelmente a difusão de informações e acesso aos meios de transporte. Nestes ambientes, é cada vez mais comum que as migrações tenham um caráter reversível (Domenach e Picouet, 1990). Da mesma forma, a ideia que o migrante cumpre determinadas etapas até chegar aos grandes centros deve ser 
revista à luz do aumento da circularidade e da crescente evasão de migrantes qualificados das áreas metropolitanas, pelo menos no caso brasileiro.

A clássica dicotomia entre áreas de atração e repulsão migratória representa cada vez menos o caso brasileiro. Baeninger (2012) sugere ser mais adequado falar em áreas de retenção e áreas de perdas migratórias, considerando que esse status pode se alterar em pouco tempo. Utilizando as trocas migratórias interestaduais, a autora sugere que as áreas metropolitanas do Rio de Janeiro e São Paulo na verdade são áreas de rotatividade migratória. Evidências similares foram encontradas em Lima e Braga (2013) com a utilização de dados da migração intermunicipal. O modelo aplicado resultou em 27 aglomerações urbanas com caraterísticas rotativas, ou seja, que apresentavam simultaneamente valores altos de imigração e emigração.

A reflexão aqui proposta é precisamente sobre essas novas tendências. É inequívoco que as regiões metropolitanas têm participado da rede migratória brasileira de forma diversa do previsto nas teorias clássicas. Considerar o aumento da circularidade e o caráter reversível das migrações atuais exige uma compreensão mais detalhada sobre quem são essas pessoas que entram e saem em grande quantidade das metrópoles brasileiras. Os recém-chegados ocupam o mesmo papel social dos recém-saídos? Como atua a seletividade nas metrópoles e nas áreas de destino dos seus emigrantes? Os dados apresentados a seguir buscam esclarecer parcialmente estas questões.

\section{Dados e métodos}

As informações sobre imigrantes e emigrantes das metrópoles podem ser obtidas a partir dos microdados da amostra do Censo Demográfico do IBGE. Entre os quesitos de migração optou-se pela utilização dos migrantes de data-fixa, que são aqueles que declararam que o município de residência há cinco anos antes da data de referência do censo era diferente daquele em que residiam na data de referência. A escolha deste tipo de abordagem explicase pela importância de avaliar os saldos migratórios nos períodos de análise. 
Avaliar como a migração interna brasileira se comporta ao longo do tempo é essencial na problemática aqui colocada. Neste sentido, optou-se por realizar uma comparação entre imigrantes e emigrantes das metrópoles com os dados dos Censos de 1991 e 2010. Esse intervalo de quase vinte anos permitiu visualizar as transformações no volume e intensidade dos fluxos e também no perfil dos migrantes, de modo a indicar a tendência das mudanças que se pretende discutir neste artigo.

Outro problema metodológico refere-se à escolha das regiões metropolitanas que irão compor a análise. Conforme situação vigente em 31/12/2014, o Brasil contava com 66 regiões metropolitanas institucionalizadas. Até a década de 1990 o país possuía apenas nove aglomerados metropolitanos reconhecidos por lei. Contudo, como a Constituição de 1988 conferiu aos Estados o poder de criação de metrópoles, um processo de multiplicação de áreas metropolitanas acelerou-se mediante o uso de diferentes critérios ${ }^{3}$. Diante desse conjunto tão diverso de aglomerados, considerou-se mais conveniente recorrer a algum critério de seleção que permitisse trabalhar apenas com as regiões metropolitanas cujas características estivessem mais consolidadas. A opção foi adotar apenas os 12 aglomerados que receberam a denominação de metrópoles na publicação Regiões de Influência das Cidades $2007^{4}$ (IBGE, 2008).

Desta forma, denominam-se aqui imigrantes das metrópoles os indivíduos que residiam nas 12 áreas selecionadas na data de referência do censo e declaram que exatamente há cinco anos antes residiam em algum município fora destas aglomerações. Os emigrantes das metrópoles, por sua vez, são aqueles que declararam residência nos 12 aglomerados em 1986 e 2005 e residiam fora destes espaços em 1991 e 2010. Neste sentido, a expressão Resto do Brasil faz referência a qualquer município brasileiro que não seja parte das 12 metrópoles selecionadas.

A construção das tabelas e gráficos permite a comparação em cada Censo do perfil de imigrantes e emigrantes simultaneamente à comparação da situação destes entre 1991 e 2000. A partir de outras informações censitárias foi possível cruzar dados demográficos (sexo, idade e posição no domicílio) e socioeconômicos (educação, trabalho e renda) de

\footnotetext{
${ }^{3}$ Sobre a falta de correspondência entre a institucionalidade e a espacialidade, consultar Barreto (2012).

${ }^{4}$ São eles: Manaus, Belém, Fortaleza, Recife, Salvador, Belo Horizonte, Rio de Janeiro, São Paulo, Curitiba e Porto Alegre, Goiânia e Brasília. As metrópoles aqui foram consideradas excluindo as áreas de expansão.
} 
modo a inferir quais são as diferenças entre os que entram e saem das metrópoles, bem como que mudanças principais ocorreram no perfil destas populações ao longo dos 20 anos analisados.

\section{Resultados e Discussão}

Cumpre inicialmente tratar dos contingentes demográficos envolvidos na migração em análise. A Tabela 1 traz uma síntese dos fluxos migratórios envolvendo as regiões metropolitanas e o resto do Brasil em 1991 e 2010. As migrações internas brasileiras ainda envolvem tamanhos demográficos consideráveis e têm crescido em termos absolutos ao longo do período. Em 1991, os migrantes de data-fixa totalizaram 13,9 milhões de pessoas, valor que sobe para 18,2 milhões em 2010. Em termos de representatividade na população total, contudo, os migrantes de 1991 eram 9,5\% dos 146 milhões de habitantes, enquanto os migrantes de 2010 são 9,5\% de 190 milhões de pessoas. Isso indica que a migração vem se mantendo dinâmica nas últimas décadas, ainda que os dados do Censo 2000 tenham mostrado pequena redução proporcional dos fluxos, recuperada na década seguinte 5 .

\begin{tabular}{|c|c|c|c|c|}
\hline \multirow{2}{*}{ Categorias } & \multicolumn{2}{|l|}{1991} & \multicolumn{2}{|l|}{2010} \\
\hline & População & $\%$ & População & $\%$ \\
\hline Migrantes trocados entre o Resto do Brasil & $7,888,267$ & 56.4 & $10,785,625$ & 59.1 \\
\hline Migrantes trocados entre as RMs & 437,691 & 3.1 & 381,988 & 2.1 \\
\hline Imigrantes das metrópoles & $2,476,936$ & 17.7 & $2,166,374$ & 11.9 \\
\hline Emigrantes das metrópoles & $1,634,561$ & 11.7 & $1,874,371$ & 10.3 \\
\hline Migrantes intra-metropolitanos & $1,545,492$ & 11.1 & $3,029,805$ & 16.6 \\
\hline Total de Migrantes de Data-Fixa & $13,982,947$ & & $18,238,163$ & \\
\hline Saldo das RMs nas trocas com o resto do Brasil & 842,375 & & 292,003 & \\
\hline
\end{tabular}

Tabela 1: Síntese das trocas migratórias entre as regiões metropolitanas e o resto do Brasil Fonte: Censo Demográficos de 1991 e 2010

\footnotetext{
${ }^{5}$ Segundo os dados do Censo de 2000, os migrantes de data fixa eram 15.458.886 pessoas, representando 9,1\% da população brasileira (169 milhões). A queda relativa foi pequena, mas a recuperação ocorrida na década seguinte parece suportar a hipótese que o crescimento econômico e a mobilidade social da primeira década do século XXI conferiram novo fôlego às migrações internas.
} 
Essa informação sobre o peso dos migrantes na população total tem um significado importante. Como as análises subsequentes vão demonstrar, houve mudanças significativas na composição e intensidade de determinados fluxos migratórios que não podem ser atribuídas a uma diminuição do dinamismo da migração interna. Os movimentos populacionais mantêm sua importância na redistribuição da população mesmo depois da população urbana ter se tornado predominante no território ${ }^{6}$.

Com relação às trocas entre as 12 metrópoles e o resto do Brasil, há duas tendências muito claras. A primeira é que ocorreu aumento das migrações internas que não envolvem as regiões metropolitanas mais importantes do país. Em 1991, os migrantes trocados entre os municípios do resto do Brasil representavam 56\% do total dos fluxos, passando a $59 \%$ em 2010, ao mesmo tempo nota-se uma diminuição dos migrantes trocados entre as RMs, de 437 mil para 381 mil pessoas. A segunda tendência, fundamental para a discussão aqui proposta, é a redução do saldo migratório das metrópoles de 842 mil em 1991 para 292 mil em 2010. Vale destacar que essa redução deve-se, simultaneamente, à diminuição do total de imigrantes e ao aumento do total de emigrantes. Esse é um fato muito relevante para as migrações internas brasileiras. Historicamente, foram as metrópoles que comandaram o processo de redistribuição populacional como os mais importantes espaços de atração. Assim, os sinais da mudança são claros quando a tendência do saldo migratório dos centros urbanos mais importantes do país é se tornar negativo. O Gráfico 1 confirma essa tendência, apresentado os saldos de cada uma das 12 metrópoles.

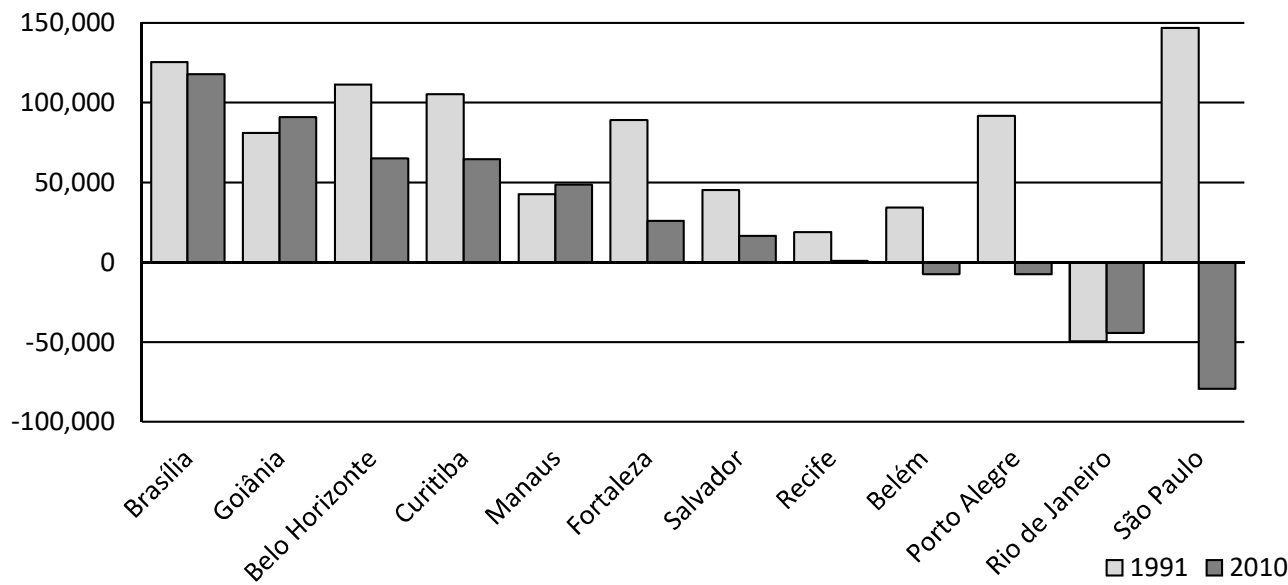

Gráfico 1: Saldo migratório das trocas entre as regiões metropolitanas e o resto do Brasil para os migrantes de data-fixa nos períodos 1986-91 e 2005-10

Fonte: Censos Demográficos de 1991 e 2010

\footnotetext{
${ }^{6} \mathrm{Em} 1991$, a população urbana brasileira correspondia a 75,5\% da população total. Em 2010, esse percentual alcançou $84,4 \%$.
} 
As metrópoles estão organizadas no gráfico de acordo com o valor do saldo em 2010 . A exceção de Goiânia e Manaus, todas as aglomerações mostraram tendência de redução no valor dos saldos. Não há dúvida que parte importante da redução global deve-se ao comportamento da metrópole paulista, que passou do maior valor de saldo positivo em 1991 para o menor valor de saldo negativo em 2010. Caso seja possível assumir que Rio de Janeiro e São Paulo indicam uma tendência futura para as metrópoles, o que provavelmente vai demorar a ocorrer no caso dos centros nas regiões Norte e Centro-Oeste, não seria surpreendente que o Censo de 2020 mostrasse saldo negativo nas trocas destas metrópoles com o resto do Brasil.

Esse conjunto de evidências traz importantes questões sobre o papel atual das metrópoles na rede migratória brasileira, renovando o debate sobre a contribuição destes espaços na reestruturação da economia e território no Brasil. Segue então, uma análise sobre o perfil das populações que entram e saem das metrópoles.

\subsection{Perfil dos imigrantes e emigrantes das metrópoles em 1991 e 2010}

A distribuição por sexo indica a primeira diferença importante entre imigrantes e emigrantes. Entre aqueles que entraram nas metrópoles, as mulheres são mais numerosas, com cerca de 1,3 milhão de pessoas (52,5\%) em 1991 e 1,1 milhão em 2010 (51,7\%), ao passo que os homens são o maior grupo entre os emigrantes, com 819 mil em 1991 (50,1\%) e 942 mil em 2010 (50,3\%). Não há grandes discrepâncias na distribuição por sexo nos dois grupos, mas fica claro que o maior desequilíbrio situa-se nos imigrantes, com vantagem para as mulheres.

Outra variável demográfica fundamental é a idade, representada no Gráfico 2. Evidentemente a distinção mais notável encontra-se entre imigrantes e emigrantes. Os indivíduos que entraram nas RMs mostram alta concentração na faixa etária entre 20 a 24 anos de idade, enquanto os emigrantes encontram-se mais distribuídos entre as faixas etárias. A distribuição dos emigrantes em 1991 sugere que esse movimento possuía forte perfil familiar, com a maior concentração entre as crianças de 5 a 9 anos. A estrutura das curvas muda pouco entre um período e outro, mas tanto no caso dos imigrantes quanto dos 
emigrantes a mudança reflete o envelhecimento destas populações. A idade média dos grupos aumentou quatro anos entre 1991 e 2010, no caso dos imigrantes subiu de 25,4 para 29 anos e no caso dos emigrantes de 28,2 para 32,4 anos.

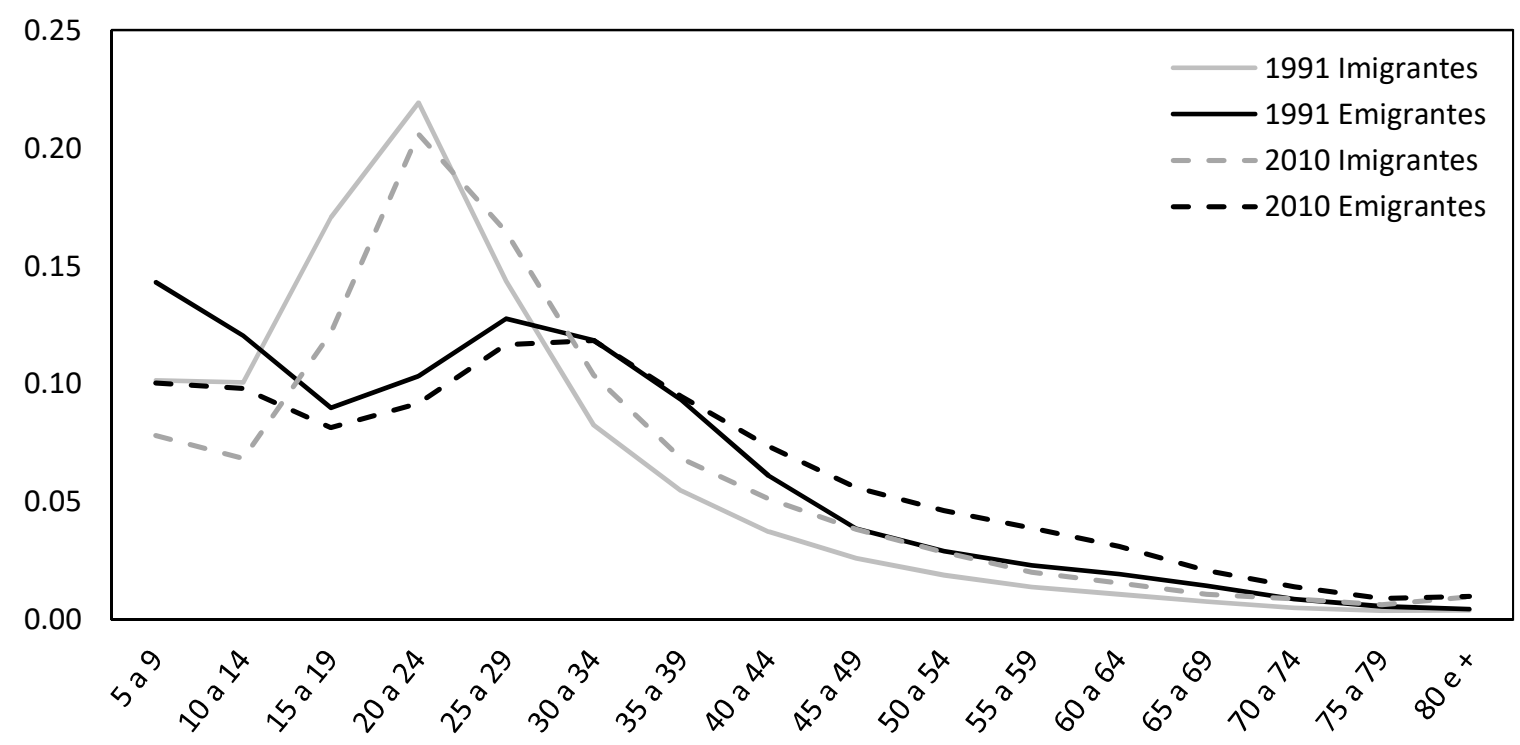

Gráfico 2: Estrutura etária dos imigrantes e emigrantes das metrópoles em 1991 e 2010 Fonte: Censos Demográficos de 1991 e 2010

Como a estrutura das curvas fica praticamente inalterada, é provável que as mudanças no perfil etário dos migrantes se expliquem pela influência da transição demográfica brasileira. Além do envelhecimento, é notória a diminuição dos emigrantes entre 5 e 9 anos, sem dúvida um reflexo da diminuição da fecundidade. De qualquer forma, os dados permitem afirmar que a imigração para as metrópoles cumpre papel de rejuvenescer a estrutura etária dos aglomerados, enquanto os emigrantes tendem a ser um pouco mais velhos e a se movimentar junto com a família. Para confirmar essa hipótese, contudo, cabe considerar o perfil da participação domiciliar dos migrantes, de modo a entender em que contexto se dão os movimentos.

A Tabela 2 apresenta os dados de posição dos imigrantes e emigrantes nos seus domicílios segundo o sexo. Mais uma vez, as informações confirmam a hipótese de que as mudanças no perfil das migrações se devem a um conjunto mais amplo de mudanças demográficas, quais sejam, os impactos da redução da fecundidade (que aparecem na diminuição da participação de filhos em todos os grupos) e a reorganização das estruturas familiares, que 
pode ser observada no aumento combinado de duas categorias: o percentual de homens como cônjuges e o percentual de mulheres como responsável pelo domicílio.

\begin{tabular}{|c|c|c|c|c|c|c|c|c|}
\hline \multirow{3}{*}{ Posição no domicílio } & \multicolumn{4}{|c|}{ Imigrantes } & \multicolumn{4}{|c|}{ Emigrantes } \\
\hline & Homens & \begin{tabular}{l|l}
$\%$ & \\
\end{tabular} & Mulheres & $\%$ & Homens & \begin{tabular}{l|l}
$\%$ & \\
\end{tabular} & Mulheres & $\%$ \\
\hline & \multicolumn{8}{|c|}{1991} \\
\hline Pessoa responsável & 469,061 & 39.9 & 84,092 & 6.5 & 394,261 & 48.1 & 71,212 & 8.7 \\
\hline Cônjuge, companheiro(a) & 7,651 & 0.7 & 451,306 & 34.7 & 4,423 & 0.5 & 342,654 & 42.0 \\
\hline Filho(a), enteado(a) & 332,153 & 28.2 & 305,500 & 23.5 & 294,551 & 36.0 & 273,798 & 33.6 \\
\hline Outro* & 367,291 & 31.2 & 459,882 & 35.4 & 126,091 & 15.4 & 127,573 & 15.6 \\
\hline \multirow[t]{2}{*}{ Total } & $1,176,156$ & & $1,300,780$ & & 819,326 & & 815,237 & \\
\hline & \multicolumn{8}{|c|}{2010} \\
\hline Pessoa responsável & 399,033 & 33.9 & 261,209 & 20.1 & 405,743 & 49.5 & 218,257 & 26.8 \\
\hline Cônjuge, companheiro(a) & 114,454 & 9.7 & 333,643 & 25.6 & 97,621 & 11.9 & 317,617 & 39.0 \\
\hline Filho(a), enteado(a) & 233,842 & 19.9 & 220,715 & 17.0 & 272,967 & 33.3 & 254,054 & 31.2 \\
\hline Outro* & 299,670 & 25.5 & 303,811 & 23.4 & 166,182 & 20.3 & 141,930 & 17.4 \\
\hline Total & $1,046,999$ & & $1,119,378$ & & 942,513 & & 931,858 & \\
\hline
\end{tabular}

Tabela 2: Distribuição dos migrantes das metrópoles segundo posição no domicílio de residência e sexo em 1991 e 2010

Fonte: Censo Demográficos de 1991 e 2010. * Pais, netos, irmãos, agregado, pensionista, empregado e individual

No tocante às diferenças entre imigrantes e emigrantes, os percentuais na tabela estão marcados em negrito para os grupos com maiores valores, sempre na comparação entre as categorias de imigrantes e emigrantes. As categorias de responsável e cônjuge concentram a maior parte desta população, como era de se esperar pela predominância de jovens adultos. A diferença principal pode ser notada em duas categorias: os imigrantes aparecem mais bem representados na categoria Outro e os emigrantes na categoria Filhos. Isso parece indicar que entre os imigrantes são mais comuns os movimentos de jovens adultos sem filhos e a alocação em domicílios na condição de parente ou agregado, muito embora a categoria outro tenha-se reduzido cerca de 10 pontos percentuais entre 1991 e 2010 . No caso dos emigrantes, os dados indicam ser mais comum a migração familiar, justamente pela maior representatividade das categorias responsável, cônjuge e filhos.

Resta ainda comparar imigrantes e emigrantes em indicadores socioeconômicos, a fim de refletir sobre a contribuição destes nos lugares de destino. A inserção econômica dos migrantes das metrópoles tem alguns traços bem distintos. Contudo, há um aspecto metodológico que precisa ser destacado. A forma de captação da população ocupada no 
Censo de 1991 foi diferente daquela utilizada no Censo de 2010. No primeiro censo, perguntou-se aos entrevistados se eles haviam trabalhado nos últimos 12 meses anteriores à data de referência da pesquisa. Por sua vez, a pesquisa de 2010 questiona se os entrevistados possuíam trabalho na semana anterior à data de referência. Dada essa diferença é de se esperar que 2010 possua subenumeração em comparação com a metodologia utilizada em 1991.

É precisamente isso que acontece. Entre os imigrantes das metrópoles, registrou-se cerca de 1,2 milhões de pessoas com trabalho em 1991, contra $701 \mathrm{mil}$ em 2010. No caso dos emigrantes, essa diferença foi de 1,1 milhões contra 874 mil. Como não é possível dimensionar o significado destas diferenças (já que a metodologia de coleta foi diferente) a análise aqui vai tratar apenas da distribuição percentual destes indivíduos em classes de ocupação e atividade, que provavelmente sofre pouco impacto da mudança na forma da pergunta.

A distribuição dos migrantes em grupos de ocupação e atividade mostram importantes diferenças na inserção econômica entre os que entram e saem das metrópoles. As ocupações com baixa exigência de qualificação na indústria e nos serviços ${ }^{7}$ reuniram $66,2 \%$ dos imigrantes e 55,2\% dos emigrantes em 1991. Em 2010, esses percentuais são reduzidos para 55,2 e 46,3\%, respectivamente. Os imigrantes ainda superam os emigrantes entre os trabalhadores agropecuários e os trabalhadores de manutenção e reparação em ambos os períodos. Os emigrantes se destacam nas categorias com maior exigência de qualificação. Em 1991, os ocupados na categoria profissionais das ciências e das artes eram 4,7\% entre os imigrantes e $10,9 \%$ entre os emigrantes, e esses percentuais subiram para $9,4 \%$ entre imigrantes e 13,2\% entre emigrantes em 2010. Padrão similar ocorreu entre os técnicos de nível médio, que concentravam 6,1\% dos emigrantes em 1991, contra 3,9\% de imigrantes. Em 2010 os imigrantes dessa categoria representavam 6,9\% e os emigrantes 7,8\%. Quanto à distribuição dos migrantes entre os setores de atividade, os imigrantes são mais representativos do que os emigrantes principalmente na indústria da construção $(20,9$ contra 12,8\% em 1991 e 16,2 contra 14,8\% em 2010) e nos serviços domésticos (18,1 contra

\footnotetext{
${ }^{7}$ São as categorias: Trabalhadores dos serviços, vendedores do comércio em lojas e mercados e Trabalhadores da produção de bens e serviços industriais.
} 
9,9\% em 1991 e 7,3 contra 5,4\% em 2010). Os emigrantes, por sua vez, se destacam com participações mais elevadas nos setores de comércio de mercadorias, prestação de serviços (apenas em 1991) e administração pública ${ }^{8}$.

Esses dados mostram evidências de que as trocas populacionais das metrópoles representam mudanças no perfil da população ocupada. Aqueles que entram nas metrópoles tendem a se concentrar mais em atividades de baixa qualificação na indústria e no setor de serviços, ao passo que os emigrantes parecem contribuir para aumentar a qualificação dos ocupados nas localidades fora das metrópoles que os recebem. Os emigrantes se destacam em ocupações com médio e alto grau de escolaridade e se inserem predominantemente no setor de serviços. Cabe destacar, contudo, que as diferenças na distribuição de imigrantes e emigrantes tenderam a diminuir entre 1991 e 2010, especialmente pelo aumento da participação de ambos os grupos em ocupações mais qualificadas (profissionais das ciências e das artes e técnicos de nível médio) e pelo crescimento de alguns setores como educação e serviços sociais, atividades agropecuárias e administração pública.

Essa mudança geral no perfil da inserção econômica provavelmente tem forte correlação com mudanças no status da escolaridade. De qualquer forma, a comparação entre imigrantes e emigrantes sugere que estes são relativamente mais escolarizados, já que têm maior participação em trabalhos mais qualificados. Nas Tabelas 3 e 4, pode-se conferir a distribuição dos imigrantes e emigrantes em níveis de escolaridade por categorias de ocupação e setor de atividade no trabalho principal. Os dados confirmam a hipótese de que os emigrantes têm nível de escolaridade mais elevado do que os não migrantes e não apenas pela sua melhor representatividade em ocupações qualificadas. De fato, em praticamente todas as categorias de ocupação e atividade os emigrantes se mostram mais escolarizados do que os imigrantes.

Os dados também revelam um inequívoco processo de expansão do nível de escolaridade dos migrantes. Em 1991 (Tabela 3), a participação de trabalhadores com baixa escolaridade

\footnotetext{
${ }^{8}$ O setor de comércio de mercadorias reunia 17,1\% dos emigrantes em 1991, contra 13,5\% de imigrantes, em 2010 os valores eram, respectivamente, 16,5 e 15,2\%. No setor de prestação de serviços, os emigrantes eram $22,3 \%$, em 1991, e 19,6\%, em 2010, entre os imigrantes os valores foram 19,1 e $20,5 \%$. No setor de administração pública, concentrava 4,5 dos emigrantes, em 1991, e 7,1\% em 2010. No caso dos imigrantes, o setor reunia 2,7\%, em 1991, e 6,2\% em 2010.
} 
(sem instrução e fundamental incompleto) nas ocupações de baixa qualificação (trabalhadores da indústria, serviços e agropecuária) mostram valores próximos a $80 \%$. Em 2010 (Tabela 4), essas participações caem drasticamente para patamares próximos de 40\%, a exceção dos trabalhadores agropecuários, entre os quais cerca de $70 \%$ possuíam baixa escolaridade. A participação de ocupados com curso superior completo apresentou aumentos significativos no período, tanto para imigrantes como para emigrantes, com destaque para as ocupações de maior qualificação (Membros das forças armadas, policiais e bombeiros militares; Membros superiores do poder público, dirigentes e gerentes de organizações; Profissionais das ciências e das artes; Técnicos de nível médio) e nos setores de Educação, saúde e serviços sociais e Administração pública.

A ampliação geral da escolaridade teve papel importante para reduzir os diferenciais entre imigrantes e emigrantes. Além disso, como os emigrantes tem perfil etário mais envelhecido, parte destas diferenças também se explica pela idade média mais elevada. Não obstante, os dados das Tabelas 3 e 4 confirmam que as trocas populacionais entre as metrópoles contribuem para saída de população mais qualificada e entrada de jovens com menos escolaridade, muito embora a tendência no tempo seja de redução progressiva destas diferenças, o que indica que os novos migrantes das metrópoles tiveram acesso à escolaridade nas áreas de origem.

É possível que o aumento da oferta de educação nas localidades fora das metrópoles (Tabela 1) seja uma das razões para a redução absoluta no número de imigrantes entre 1991 e 2010. (ver BARBOSA, A. M. et. all, 2015). Considerando a migração como um esforço de investimento em capital humano, a ampliação das oportunidades de qualificação em municípios não-metropolitanos aumenta o risco associado ao movimento para as metrópoles. Não obstante, os dados ainda mostram que a migração permanece dinâmica em todas as metrópoles e que a maioria dos 12 espaços selecionados tem saldos migratórios positivos em 2010. Isso levanta a questão sobre os diferenciais de renda entre as metrópoles e os municípios do resto do Brasil. 


\begin{tabular}{|c|c|c|c|c|c|c|c|c|}
\hline \multirow[b]{2}{*}{ Ocupação no trabalho principal } & \multicolumn{4}{|c|}{ Imigrantes } & \multicolumn{4}{|c|}{ Emigrantes } \\
\hline & $\begin{array}{c}\text { Sem } \\
\text { instrução e } \\
\text { fundamental } \\
\text { incompleto }\end{array}$ & $\begin{array}{c}\text { Fundamental } \\
\text { completo e } \\
\text { médio } \\
\text { incompleto }\end{array}$ & $\begin{array}{c}\text { Médio } \\
\text { completo e } \\
\text { superior } \\
\text { incompleto }\end{array}$ & $\begin{array}{l}\text { Superior } \\
\text { completo }\end{array}$ & $\begin{array}{c}\text { Sem } \\
\text { instrução e } \\
\text { fundamental } \\
\text { incompleto }\end{array}$ & $\begin{array}{c}\text { Fundamental } \\
\text { completo e } \\
\text { médio } \\
\text { incompleto }\end{array}$ & $\begin{array}{c}\text { Médio } \\
\text { completo e } \\
\text { superior } \\
\text { incompleto }\end{array}$ & $\begin{array}{l}\text { Superior } \\
\text { completo }\end{array}$ \\
\hline Membros das forças armadas, policiais e bombeiros militares & 10.5 & 29.4 & 41.7 & 18.4 & 8.8 & 28.0 & 47.5 & 15.6 \\
\hline Membros superiores do poder público, dirigentes e gerentes de organizações & 24.3 & 14.3 & 33.7 & 27.6 & 21.4 & 15.2 & 36.4 & 27.0 \\
\hline Profissionais das ciências e das artes & 7.8 & 8.0 & 31.3 & 52.9 & 6.9 & 7.2 & 23.8 & 62.1 \\
\hline Técnicos de nível médio & 24.4 & 16.2 & 44.9 & 14.5 & 19.0 & 16.2 & 45.9 & 18.9 \\
\hline Trabalhadores de serviços administrativos & 28.5 & 24.3 & 42.0 & 5.1 & 20.7 & 25.2 & 42.5 & 11.5 \\
\hline Trabalhadores dos serviços, vendedores do comércio em lojas e mercados & 77.9 & 12.2 & 8.3 & 1.3 & 63.8 & 18.0 & 15.2 & 2.8 \\
\hline Trabalhadores agropecuários, florestais, caça e pesca & 93.0 & 3.6 & 2.8 & 0.6 & 89.1 & 6.1 & 3.5 & 1.3 \\
\hline Trabalhadores da produção de bens e serviços industriais & 82.1 & 11.5 & 5.3 & 1.0 & 74.8 & 15.1 & 8.8 & 1.3 \\
\hline Trabalhadores de reparação e manutenção & $\mathbf{7 7 . 4}$ & 13.1 & 8.4 & 1.0 & 63.6 & 18.9 & 15.4 & 1.9 \\
\hline \multicolumn{9}{|l|}{ Setor de atividade do trabalho principal } \\
\hline Atividades agropecuárias, exploração vegetal e pesca & 89.3 & 4.5 & 4.3 & 1.8 & 83.7 & 6.8 & 6.2 & 3.3 \\
\hline Indústrias da transformação, extrativas e de serviços de utilidade pública & 70.8 & 14.4 & 10.8 & 3.9 & 54.6 & 17.0 & 18.0 & 10.4 \\
\hline Indústria da construção & 87.0 & 6.7 & 4.0 & 2.3 & 77.6 & 10.1 & 7.7 & 4.5 \\
\hline Comércio de mercadorias & 59.0 & 18.6 & 19.2 & 3.1 & 44.4 & 22.1 & 26.0 & 7.4 \\
\hline Transporte e comunicação & 66.6 & 17.1 & 12.8 & 3.4 & 57.5 & 19.5 & 17.5 & 5.5 \\
\hline Prestação de serviço. Serviços coletivos, pessoais e auxiliares & 59.3 & 15.0 & 19.1 & 6.5 & 46.4 & 17.9 & 24.1 & 11.5 \\
\hline Serviços domésticos & 88.7 & 7.5 & 2.7 & 0.6 & 88.1 & 9.0 & 2.4 & 0.3 \\
\hline Educação, saúde e serviços sociais & 22.8 & 12.2 & 34.4 & 30.6 & 14.8 & 12.6 & 32.4 & 40.1 \\
\hline Administração pública & 20.2 & 18.8 & 36.3 & 24.6 & 17.0 & 17.6 & 37.4 & 28.0 \\
\hline
\end{tabular}

Fonte: Censo Demograficos de 1991 e 2010.

* As categorias de ocupação e atividade aqui apresentadas correspondem aquelas utilizadas na classificação do Censo de 2000 . 0 artificio foi compatibilizar as classificações de 1991 e 2010 utilizando, no Censo 2000, a variável com os códigos de 1991 e no Censo de 2010 a variável com os códigos de 2000.

** A distribuição percentual apresentada refere-se aos niveis de escolaridade em cada classe, assim, os valores somam 100\% em cada linha. As marcações em negrito mostram, para cada linha, quais categorias tem participação mais elevada na comparação entre imigrantes e emigrantes

Tabela 3: Distribuição dos migrantes das metrópoles, segundo nível de escolaridade em categorias de ocupação e setores de atividade* do trabalho principal para os migrantes de data-fixa do período 1986-1991** 


\begin{tabular}{|c|c|c|c|c|c|c|c|c|}
\hline \multirow[b]{2}{*}{ Ocupação no trabalho principal } & \multicolumn{4}{|c|}{ Imigrantes } & \multicolumn{4}{|c|}{ Emigrantes } \\
\hline & \begin{tabular}{|c|} 
Sem \\
instrução e \\
fundamental \\
incompleto
\end{tabular} & $\begin{array}{c}\text { Fundamental } \\
\text { completo e } \\
\text { médio } \\
\text { incompleto }\end{array}$ & $\begin{array}{c}\text { Médio } \\
\text { completo e } \\
\text { superior } \\
\text { incompleto }\end{array}$ & $\begin{array}{l}\text { Superior } \\
\text { completo }\end{array}$ & $\begin{array}{c}\text { Sem } \\
\text { instrução e } \\
\text { fundamental } \\
\text { incompleto }\end{array}$ & $\begin{array}{c}\text { Fundamental } \\
\text { completo e } \\
\text { médio } \\
\text { incompleto }\end{array}$ & \begin{tabular}{|c} 
Médio \\
completo e \\
superior \\
incompleto
\end{tabular} & $\begin{array}{c}\text { Superior } \\
\text { completo }\end{array}$ \\
\hline Membros das forças armadas, policiais e bombeiros militares & 3.4 & 6.3 & 52.5 & 37.7 & 1.7 & 4.6 & 55.5 & 38.1 \\
\hline Membros superiores do poder público, dirigentes e gerentes de organizações & 9.4 & 9.2 & 36.3 & 45.1 & 10.2 & 10.2 & 38.0 & 41.4 \\
\hline Profissionais das ciências e das artes & 3.8 & 3.6 & 21.2 & 71.0 & 4.0 & 4.4 & 18.8 & 72.8 \\
\hline Técnicos de nível médio & 9.3 & 12.1 & 53.2 & 24.7 & 7.1 & 11.1 & 54.4 & 27.0 \\
\hline Trabalhadores de serviços administrativos & 10.6 & 17.4 & 59.0 & 12.3 & 8.7 & 15.3 & 59.1 & 16.3 \\
\hline Trabalhadores dos serviços, vendedores do comércio em lojas e mercados & 39.1 & 24.8 & 32.9 & 2.5 & 35.6 & 24.1 & 34.8 & 5.2 \\
\hline Trabalhadores agropecuários, florestais, caça e pesca & 70.0 & 15.9 & 11.8 & 2.1 & 65.9 & 17.4 & 14.1 & 2.3 \\
\hline Trabalhadores da produção de bens e serviços industriais & 49.6 & 24.1 & 24.7 & 1.1 & 44.3 & 25.5 & 27.6 & 2.3 \\
\hline Trabalhadores de reparação e manutenção & 36.6 & 26.5 & 33.8 & 2.8 & 34.6 & 24.8 & 36.1 & 4.2 \\
\hline \multicolumn{9}{|l|}{ Setor de atividade do trabalho principal } \\
\hline Atividades agropecuárias, exploração vegetal e pesca & 64.0 & 15.9 & 14.1 & 5.8 & 62.3 & 17.2 & 15.6 & 4.6 \\
\hline Indústrias da transformação, extrativas e de serviços de utilidade pública & 28.8 & 21.8 & 37.4 & 11.3 & 26.8 & 21.3 & 36.8 & 14.8 \\
\hline Indústria da construção & 57.9 & 21.3 & 16.5 & 4.1 & 52.6 & 21.4 & 20.0 & 5.9 \\
\hline Comércio de mercadorias & 25.9 & 22.7 & 43.6 & 7.1 & 23.9 & 21.0 & 43.5 & 11.3 \\
\hline Transporte e comunicação & 29.5 & 20.0 & 39.3 & 10.7 & 27.9 & 20.6 & 40.7 & 10.6 \\
\hline Prestação de serviço. Serviços coletivos, pessoais e auxiliares & 23.6 & 18.4 & 38.0 & 19.4 & 20.2 & 18.6 & 37.7 & 23.1 \\
\hline Serviços domésticos & 49.7 & 25.3 & 24.0 & 0.6 & 54.5 & 24.9 & 19.4 & 0.8 \\
\hline Educação, saúde e serviços sociais & 6.6 & 5.7 & 33.1 & 54.2 & 5.0 & 5.9 & 30.2 & 58.7 \\
\hline Administração pública & 5.7 & 7.2 & 41.7 & 45.1 & 7.1 & 7.0 & 39.5 & 46.3 \\
\hline
\end{tabular}

Fonte: Censo Demograficos de 1991 e 2010

* As categorias de ocupação e atividade aqui apresentadas correspondem aquelas utilizadas na classificação do Censo de 2000 . 0 artificio foi compatibilizar as classificações de 1991 e 2010 utilizando, no Censo 2000, a variável com os códigos de 1991 e no Censo de 2010 a variável com os códigos de 2000.

** A distribuição percentual apresentada refere-se aos niveis de escolaridade em cada classe, assim, os valores somam 100\% em cada linha. As marcações em negrito mostram, para cada linha, quais categorias tem participação mais elevada na comparação entre imigrantes e emigrantes

Tabela 4: Distribuição dos migrantes das metrópoles, segundo nível de escolaridade em categorias de ocupação e setores de atividade* do trabalho principal para os migrantes de data-fixa do período 2005-2010** 
A Tabela 5 apresenta os valores da renda mediana auferida em 2010 pelos trabalhadores residentes nas metrópoles e no resto do Brasil segundo as categorias de ocupação e o nível de escolaridade ${ }^{1}$. Em todas as categorias, a renda metropolitana é igual ou maior que a renda no resto do Brasil, a única exceção fica para os trabalhadores agropecuários com curso superior. Mesmo que os imigrantes não possuam informação perfeita, é bem razoável supor que esses diferenciais de renda ainda exerçam poder de atração sobre os jovens que se dirigem as metrópoles. Ao mesmo tempo, é curioso notar que o aumento da emigração não se relaciona a qualquer inversão no padrão dos diferenciais de renda entre as unidades espaciais.

\begin{tabular}{|c|c|c|c|c|}
\hline \multirow[t]{2}{*}{ Ocupação no trabalho principal } & $\begin{array}{c}\text { Sem } \\
\text { instruçẩo e } \\
\text { fundamental } \\
\text { incomple to }\end{array}$ & $\begin{array}{c}\text { Fundamental } \\
\text { comple to e } \\
\text { médio } \\
\text { incomple to }\end{array}$ & $\begin{array}{c}\text { Médio } \\
\text { completoe } \\
\text { superior } \\
\text { incomple to }\end{array}$ & $\begin{array}{l}\text { Superior } \\
\text { completo }\end{array}$ \\
\hline & \multicolumn{4}{|c|}{12 metrópoles } \\
\hline Membros das forças armadas, policiais e bombeiros militares & RS 1,400 & RS 1,200 & RS 2,000 & RS 5,000 \\
\hline Membros superiores do poder público, dirigentes e gerentes de organizações & RS 1,000 & RS 1,500 & RS 2,000 & RS 4,000 \\
\hline Profissionais das ciências e das artes & RS 800 & RS 900 & RS 1,200 & RS 2,900 \\
\hline Técricos de nivel médio & RS 800 & RS 900 & RS 1,023 & RS 2,000 \\
\hline Trabalhadores de serviços administrativos & RS 700 & RS 650 & RS 780 & RS 1,500 \\
\hline Trabalhadores dos serviços, vendedores do comércio em lojas e mercados & RS 510 & RS 600 & RS 700 & RS 1,500 \\
\hline Trabalhadores agropecuários, florestais, caça e pesca & RS 300 & RS 400 & RS 510 & RS 510 \\
\hline Trabal hadores da produção de bens e serviços industriais & RS 700 & RS 800 & RS 900 & RS 1,500 \\
\hline \multirow[t]{2}{*}{ Trabalhadores de reparacãoe mamutenção } & RS 800 & RS 860 & RS 1.000 & RS 2.000 \\
\hline & \multicolumn{4}{|c|}{ Resto do Brasil } \\
\hline Membros das forças armadas, policiais e bombeiros militares & RS 1,200 & RS 1,100 & RS 1,900 & RS 3,800 \\
\hline Membros superiores do poder público, dirigentes e gerentes de organizações & RS 1,000 & RS 1,300 & RS 1,500 & RS 2,500 \\
\hline Profissionais das ciências e das artes & RS 510 & RS 700 & RS 900 & RS 1,800 \\
\hline Técricos de nivel médio & RS 700 & RS 800 & RS 900 & RS 1,500 \\
\hline Trabalhadores de serviços administrativos & RS 600 & RS 600 & RS 700 & RS 1,020 \\
\hline Trabal hadores dos serviços, vendedores do comércio em lojas e mercados & RS 510 & RS 510 & RS 600 & RS 1,020 \\
\hline Trabal hadores agropecuários, florestais, caça e pesca & RS 150 & RS 255 & RS 450 & RS 1,000 \\
\hline Trabalhadores da produção de bens e serviços industriais & RS 600 & RS 700 & RS 800 & RS 1,300 \\
\hline Trabalhadores de reparacão e mamutenção & RS 600 & RS 700 & RS 1.000 & RS 1.500 \\
\hline
\end{tabular}

Tabela 5: Renda mediana da população residente nas 12 metrópoles selecionadas e no Resto do Brasil, segundo ocupação no trabalho principal e nível de escolaridade em 2010

Fonte: Censo Demográficos de 2010

O comportamento da emigração, a princípio, sugere algo paradoxal. Os dados mostram que a inserção daqueles que saem das metrópoles no mercado de trabalho é menos precária do que a dos imigrantes, contudo são fluxos migratórios que se dirigem a espaços com

\footnotetext{
${ }^{1}$ Considerou-se desnecessário apresentar os valores do Censo de 1991, primeiramente, porque há muitos trabalhos que já mostraram, para o período, que a renda metropolitana é mais elevada. Cumpre refletir se, ainda, em 2010 os diferenciais de renda podem ter influência na migração.
} 
menores rendas medianas. Isto contradiz os modelos teóricos mais consagrados, a não ser que as taxas de reemigração tivessem-se elevado entre 1991 e $2010^{2}$.

Contudo, isso não acontece. Em 1991, os emigrantes das metrópoles que retornaram ao município de nascimento eram 306.159 (18,7\% do total de emigrantes) e os que retornaram a UF de nascimento eram 306.763 (18,8\%). Em 2010, o retorno ao município de nascimento entre os emigrantes reuniu $16 \%$ destes (299.371 pessoas) e o retorno à UF de nascimento totalizou 340.403 emigrantes (18,2\%). Desta maneira, a reemigração, em 2010, foi proporcionalmente menor. Os dados não apenas mostram que imigrantes e emigrantes das metrópoles são populações bens distintas entre si, mas que os marcos teóricos que ajudam a entender a entrada das pessoas nas metrópoles parecem pouco eficiente para explicar o porquê de as pessoas saírem. Torna-se necessário, então, prosseguir questionando quais as razões que tem levado as pessoas a sistematicamente deixarem as metrópoles e se os saldos migratórios vão continuar a cair. Sem dúvida, o recente protagonismo das cidades médias brasileiras é parte essencial dessa explicação, assim como a inclusão no rol de preferências dos migrantes de fatores não-econômicos, que promovem aumento da qualidade de vida.

\section{Considerações Finais}

Procurou-se aqui demonstrar que a participação das 12 principais metrópoles brasileiras na rede migratória interna passa por mudanças importantes, com reflexos sobre a organização da sociedade e do território. O forte poder de atração populacional destes aglomerados começa a dar lugar a um processo diferente e pouco conhecido nos estudos dos sistemas migratórios. Os valores dos saldos das metrópoles nas trocas de população com o resto do Brasil diminuíram sensivelmente entre 1991 e 2010, reflexo de um processo simultâneo de queda no número de imigrantes e aumento dos emigrantes.

\footnotetext{
${ }^{2}$ Martine (1980) mostrou que havia taxas altas de reemigração entre aqueles que entravam nas metrópoles, resultado do processo de adaptação. O retorno migratório, assim, compreende um contrafluxo normal em sistemas migratórios que tendem a direcionar os movimentos de acordo com os diferenciais regionais de renda. Os dados aqui parecem mostrar que a emigração metropolitana não se aplica a esse modelo teórico.
} 
A comparação entre os que entram e saem das metrópoles mostra que, desde a década de 1990, esses dois grupos populacionais são bem distintos no perfil demográfico e socioeconômico. No conjunto, essas diferenças permitem afirmar que imigração e emigração, apesar de parte de um mesmo processo, são dinâmicas com natureza diferenciada, com diferentes relações com a teoria.

No tocante às informações demográficas, as diferenças permitem fazer algumas afirmações sobre as populações em estudo. Os imigrantes das metrópoles são majoritariamente jovens adultos, com leve predominância de mulheres, enquanto os emigrantes são em média, um pouco mais velhos, com distribuição equilibrada entre os sexos e maior representação de migrações familiares (pais e filhos). Entre os imigrantes há mais representatividade entre indivíduos participando de domicílios não-nucleares. Entre os emigrantes, as famílias nucleares são mais comuns.

Além disso, os dados socioeconômicos mostram que os imigrantes se distribuem com mais peso entre as ocupações de baixa qualificação nos serviços e na indústria, enquanto os emigrantes se destacam com participações mais elevadas em atividades qualificadas nos serviços e no setor público em geral. Esse dado já revela que os emigrantes seriam mais qualificados e, de fato, a comparação por nível de escolaridade e ocupação confirma que, independentemente do ramo de trabalho, os emigrantes têm status educacional mais elevado.

Por certo, a população brasileira experimentou um forte aumento do seu status educacional nas últimas décadas, com evidentes reflexos na qualificação dos migrantes. A ampliação da oferta de educação fora das metrópoles, além de melhorar a escolaridade dos novos imigrantes, pode ter contribuído para a diminuição da imigração. As saídas das metrópoles, contudo, ainda parecem ser influenciadas pelos diferencias de renda nos territórios, já que o trabalho nas metrópoles, independentemente do ramo ou da escolaridade, ainda remunera melhor do que em outras partes do país (embora o custo de vida seja relativamente mais alto nas metrópoles).

Neste sentido, a imigração parece ainda dialogar com as teorias que afirmam ser a migração um efeito das diferenças de renda entre as localidades, sendo as metrópoles espaços que permitem maior investimento em capital humano e mobilidade social. A emigração, 
contudo, não dialoga bem com esses pressupostos. O aumento da saída das metrópoles não foi acompanhado por um aumento da reemigração e os dados mostram que os emigrantes são, comparativamente aos imigrantes, mais escolarizados e melhor inseridos no mercado de trabalho, a despeito da renda mediana nos municípios fora das metrópoles ter valor menor. Aqui se encontra o novo desafio teórico: compreender a emergência da emigração das metrópoles à luz das novas tendências (a transição demográfica, a desconcentração espacial da atividade econômica e a ampliação das redes técnicas no território) a fim de construir uma narrativa coerente com o que vem reorientando os sistemas migratórios brasileiros.

\section{Referências bibliográficas}

BAENINGER, R. Rotatividade Migratória: um novo olhar para as migrações internas no Brasil. Rev. Inter. Mob. Hum., Brasília, Ano XX, № 39, p. 77-100, jul./dez. 2012.

BALAN, Jorge. Migração e desenvolvimento capitalista no Brasil: ensaio de interpretação históricocomparativa. Estudos CEBRAP, São Paulo, v.5, p. 5-79, jul/set 1973.

BARBOSA, A. M.; MATOS, R.; LOBO, C. Cidades médias e atração de migrantes qualificados. Geosul, v. 30, p. 6988, 2015.

BARRETO, I. J. O surgimento de novas regiões metropolitanas no Brasil: uma discussão a respeito do caso de Sorocaba (SP). Espaço e Economia, Ano 1, Número 1, 2012.

BECKER, B. Modernidade e gestão do território no Brasil: da integração nacional à integração competitiva. Espaço e Debates, São Paulo, n.31, p.47-56, 1991.

BIAGIONI, D. Migração e mobilidade social no estado de São Paulo em 1996: inserção dos migrantes na estrutura de classes sociais. In: Encontro Nacional sobre Migrações, 6., 2009. Belo Horizonte. Anais... Belo Horizonte: ABEP, 2009.

BRAGA, F., FAZITO, D. Análise de redes sociais e as conexões territoriais da migração no Brasil: padrões estruturais da migração interna entre 1980 e 2000. In: Encontro Nacional de Estudos Populacionais, 17., 2010, Caxambu. Anais... Caxambu: ABEP, 2010.

BRAGA, Fernando Gomes. Conexões territoriais e redes migratórias: uma análise dos novos padrões da migração interna e internacional no Brasil. 2011. 117 f. Tese (Doutorado em Demografia)- Centro de Desenvolvimento e Planejamento Regional, Universidade Federal de Minas Gerais, Belo Horizonte, 2011.

CANO, W. Novas Determinações sobre a Questão Regional e Urbana após 1980. Texto para Discussão, n. 193. Instituto de Economia/UNICAMP, julho de 2011.

DINIZ, C. C. Desenvolvimento poligonal no Brasil: nem desconcentração, nem continua polarização. Nova Economia. Belo Horizonte: UFMG. v.31.n.11. Setembro, 1993.

DOMENACH, H., PICOUET, M. El caráter de reversibilidad en el estudio de la Migración. Notas de Población, n. 49, 1990.

GAUDEMAR, J. P. Mobilidade do trabalho e acumulação do capital. Lisboa: Editorial Estampa, 1977. 
GRAHAM, Douglas H.; HOLANDA FILHO, Sergio Buarque de. As migrações inter-regionais e urbanas e o crescimento econômico do Brasil. In: MOURA, H. (Org.). Migração Interna: textos selecionados. Fortaleza: Banco do Nordeste do Brasil, 1980. v. 2. p. 733-778.

IBGE, Instituto Brasileiro de Geografia e Estatística. Regiões de Influência das Cidades 2007. Rio de Janeiro: IBGE, 2008.

JANUZZI, P. M. Mobilidade social e migração no Brasil: revisão bibliográfica e elementos empíricos para análise. Revista Brasileira de Estudos de População, Brasília, 16, n.1/2 jan./dez. 1999.

LIMA, E. E. C., BRAGA, F. G. Da rotatividade migratória à baixa migração: uma análise dos padrões da mobilidade populacional no Brasil de 1995-2000. Revista Brasileira de Estudos de População, Rio de Janeiro, v. 30, n. 1, p. 57-75, jan./jun. 2013.

MARTINE, G. A redistribuição espacial da população brasileira durante a década de 1980. Texto para Discussão № 329. Brasília: IPEA, 1994.

MARTINE, G. Adaptação dos migrantes ou sobrevivência dos mais fortes?. In: MOURA, H. A. Migração interna: textos selecionados. Fortaleza: Banco do Nordeste do Brasil, 1980, p. 955-974.

MARTINE, G. Êxodo rural, concentração urbana e fronteira agrícola. In: MARTINE, G.; GARCIA, Ronaldo. Os impactos sociais da modernização agrícola. São Paulo: Caetés/Hucitec, 1987. p.59-80.

MATOS, R. A contribuição dos imigrantes em áreas de desconcentração demográfica do Brasil contemporâneo. Revista Brasileira de Estudos de População, Campinas, v. 19, n. 1, p. 49-74, jan./jun. 2002.

MATOS, R. Questões teóricas acerca dos processos de concentração e desconcentração da população no espaço. Revista Brasileira de Estudos de População, Campinas, 12(1/2), 1995.

NETTO JUNIOR, J. L. S., TARGINO, I. Migrações e diferenciais de renda estaduais: uma análise por dados em painel no período de 1950 - 2000. In: ENCONTRO TRANSDISCIPLINAR ESPAÇO E POPULAÇÃO, 1., 2003. Campinas. Anais... Campinas: ABEP, 2003.

RAMOS, C. A., ARAÚJO, H. Fluxos migratórios, desemprego e diferenciais de renda. Texto para Discussão № 657. Rio de Janeiro: IPEA, 1999.

RAVENSTEIN, E. G. As leis da migração. In: MOURA, H. A. de (Ed.). Migração interna: textos selecionados. Fortaleza: Banco do Nordeste. 1980. p.19-88.

SINGER, P. Economia política da urbanização. 10 ed. São Paulo: Brasiliense, 1985. 